\title{
Structural, elastic, and electronic properties of topological insulators: $\mathrm{Sb}_{2} \mathrm{Te}_{3}$ and $\mathrm{Bi}_{2} \mathrm{Te}_{3}$
}

\author{
Husnu Koc \\ Department of Physics, Siirt University, 56100 Siirt, \\ Turkey \\ husnu_01_12@bilkent.edu.tr
}

\author{
Amirullah M.Mamedov, Ekmel Ozbay \\ Nanotechnology Research Center (NANOTAM) \\ Bilkent University \\ 06800, Ankara, Turkey \\ mamedov@bilkent.edu.tr, ozbay@bilkent.edu.tr
}

\begin{abstract}
We have performed a first principles study of structural, elastic, and electronic properties of rhombohedral $\mathrm{Sb}_{2} \mathrm{Te}_{3}$ and $\mathrm{Bi}_{2} \mathrm{Te}_{3}$ compounds using the density functional theory within the local density approximation. The lattice parameters of considered compounds have been calculated. The second-order elastic constants have been calculated, and the other related quantities such as the Young's modulus, shear modulus, Poisson's ratio, anisotropy factor, sound velocities, and Debye temperature have also been estimated in the present work. The calculated electronic band structure shows that $\mathrm{Sb}_{2} \mathrm{Te}_{3}$ and $\mathrm{Bi}_{2} \mathrm{Te}_{3}$ compounds have a direct forbidden band gap. Our structural estimation and some other results are in agreement with the available experimental and theoretical data.
\end{abstract}

Keywords - ab initio calculation, mechanical properties, electronic structure

\section{INTRODUCTION}

$\mathrm{Sb}_{2} \mathrm{Te}_{3}$ and $\mathrm{Bi}_{2} \mathrm{Te}_{3}$, the members of compounds with the general formula $A_{2}^{V} B_{3}^{V I}$ ( $A=\mathrm{Bi}, \mathrm{Sb}$ and $B=\mathrm{S}, \mathrm{Se}, \mathrm{Te}$ ), are narrow-bandgap semiconductors with rhombohedral layered crystal structure. $\mathrm{Sb}_{2} \mathrm{Te}_{3}$ and $\mathrm{Bi}_{2} \mathrm{Te}_{3}$ are well-known topological insulators [1-7], extraordinary thermoelectric materials at ambient temperature [8] and the possible topological superconductors [9] with surface states consisting of a single Dirac cone at the high symmetry point $-\Gamma$. All of these have made $A_{2}^{V} B_{3}^{V I}$ compounds as the subject of intensive investigation both in fundamental and applied research. These compounds possess the rhombohedral crystal structure with five atoms per unit cell belonging to the space group $D_{3 d}^{5}(R \overline{3} m) . \mathrm{Sb}_{2} \mathrm{Te}_{3}$ and $\mathrm{Bi}_{2} \mathrm{Te}_{3}$ can be used for many different applications such as power generation and cooling devices [10]. Thermoelectric power generators and cooler have many advantages over conventional refrigerators and power generators such as long life, no moving parts, no green house gases, no noise, low maintenance and high reliability [11-13].

As far as we know, no ab initio general potential calculations of the mechanical properties such as the shear modulus, Poisson's ratio, anisotropy factor, sound velocities, Debye temperature of the $\mathrm{Bi}_{2} \mathrm{Te}_{3}$ and mechanical properties of $\mathrm{Sb}_{2} \mathrm{Te}_{3}$ have been reported in detail. In the present work, we have investigated the structural, electronic, and photon energy-dependent optical properties of the $\mathrm{Sb}_{2} \mathrm{Te}_{3}$ and $\mathrm{Bi}_{2} \mathrm{Te}_{3}$.

\section{Simulation}

Our calculations have been performed using the density functional formalism and local density approximation (LDA) [16] through the Ceperley and Alder functional [17] as parameterized by Perdew and Zunger [18] for the exchangecorrelation energy in the SIESTA code $[19,20]$. This code calculates the total energies and atomic forces using a linear combination of atomic orbitals as the basis set. The basis set is based on the finite range pseudoatomic orbitals (PAOs) of the Sankey_Niklewsky type [21], generalized to include multiplezeta decays. The interactions between electrons and core ions are simulated with separable Troullier-Martins [22] normconserving pseudopotentials. We have generated atomic pseudopotentials separately for atoms, $\mathrm{Sb}, \mathrm{Bi}$ and $\mathrm{Te}$ by using the $5 \mathrm{~s}^{2} 5 \mathrm{p}^{3}, 6 \mathrm{~s}^{2} 6 \mathrm{p}^{3}$ and $5 \mathrm{~s}^{2} 5 \mathrm{p}^{4}$ configurations, respectively.

\section{A. Structural Properties}

Rhombohedral structure for $\mathrm{Sb}_{2} \mathrm{Te}_{3}$ and $\mathrm{Bi}_{2} \mathrm{Te}_{3}$, structures were considered in our calculation. The equilibrium lattice parameters have been computed minimizing the crystal's total energy calculated for the different values of lattice constant by means of Murnaghan's equation of states (eos) [23], and the results are shown in Table 1 along with the experimental and theoretical values. The lattice constants for $\mathrm{Sb}_{2} \mathrm{Te}_{3}$ and $\mathrm{Bi}_{2} \mathrm{Te}_{3}$ compounds are found to be $a=4.256 \AA, b=30.397 \AA$ and $\mathrm{a}=4.383 \AA, \mathrm{b}=30.487 \AA$, respectively. The lattice parameters obtained are in a good agreement with the experimental and theoretical values $[24,14]$. In all our calculations, we have used the computed lattice constants.

TABLE 1 . The calculated equilibrium lattice parameters (a, and $\mathrm{c}$ ) together with the theoretical and experimental values for $\mathrm{Sb}_{2} \mathrm{Te}_{3}$ and $\mathrm{Bi}_{2} \mathrm{Te}_{3}$ in fractional coordinate.

\begin{tabular}{|c|c|c|c|}
\hline Material & Reference & $a(\AA)$ & $c(\AA)$ \\
\hline $\mathrm{Sb}_{2} \mathrm{Te}_{3}$ & $\begin{array}{l}\text { Present (LDA-SIESTA) } \\
\text { Theory (GGA-FLEUR) } \\
\text { Experimental }^{\mathrm{b}}\end{array}$ & $\begin{array}{l}4.256 \\
4.440 \\
4.250\end{array}$ & $\begin{array}{l}30.397 \\
30.290 \\
30.350\end{array}$ \\
\hline $\mathrm{Bi}_{2} \mathrm{Te}_{3}$ & $\begin{array}{l}\text { Present (LDA-SIESTA) } \\
\text { Theory (GGA-FLUER) } \\
\text { Experimental }^{\mathrm{b}}\end{array}$ & $\begin{array}{l}4.383 \\
4.530 \\
4.383\end{array}$ & $\begin{array}{l}30.487 \\
30.630 \\
30.487\end{array}$ \\
\hline
\end{tabular}




\section{B. Elastic Properties}

Here, to compute the elastic constants $\left(C_{i j}\right)$, we have used the stress-strain method [25]. The present elastic constants for $\mathrm{Sb}_{2} \mathrm{Te}_{3}$ and $\mathrm{Bi}_{2} \mathrm{Te}_{3}$ are given in Table 2 along with the other theoretical and experimental results[15, 26,27].

TABLE 2. The calculated elastic constants (in GPa) for $\mathrm{Sb}_{2} \mathrm{Te}_{3}$ and $\mathrm{Bi}_{2} \mathrm{Te}_{3}$.

\begin{tabular}{llcccccc}
\hline Material & Reference & $\boldsymbol{C}_{11}$ & $\boldsymbol{C}_{33}$ & $\boldsymbol{C}_{44}$ & $\boldsymbol{C}_{66}$ & $\boldsymbol{C}_{12}$ & $\boldsymbol{C}_{13}$ \\
\hline $\mathrm{Sb}_{2} \mathrm{Te}_{3}$ & Present & 83.2 & 99.7 & 44.6 & 31.0 & 21.2 & 46.1 \\
& & & & & & & \\
$\mathrm{Bi}_{2} \mathrm{Te}_{3}$ & Present & 73.8 & 54.3 & 30.4 & 28.7 & 16.3 & 30.6 \\
& Exp. $^{\mathrm{a}}(280 \mathrm{~K})$ & 68.5 & 47.7 & 27.4 & 23.4 & - & 27.0 \\
& Exp. $^{\mathrm{a}}(0 \mathrm{~K})$ & 74.4 & 51.6 & 29.2 & 26.2 & - & 29.2 \\
& Exp. $^{\mathrm{b}}(77 \mathrm{~K})$ & 76.3 & 51.2 & 30.9 & 9.9 & - & - \\
& Theoryc $^{\mathrm{c}}(0 \mathrm{~K})$ & 69.0 & 54.8 & 28.8 & 26.7 & - & 21.6 \\
& Theory $(300 \mathrm{~K})$ & 65.4 & 50.7 & 26.5 & 25.7 & - & 19.0 \\
\hline
\end{tabular}

${ }^{2}$ Reference [30]

${ }^{\mathrm{c} R e f e r e n c e ~[15]}$

The elastic constants for $\mathrm{Bi}_{2} \mathrm{Te}_{3}$ are, generally, in accord with the theoretical and experimental results. The calculated $C_{13}$ for $\mathrm{Bi}_{2} \mathrm{Te}_{3}$ is higher than the theoretical results. The $C_{66}$ elastic constant at $77 \mathrm{~K}$ measured by Kullmann et al [27] for $\mathrm{Bi}_{2} \mathrm{Te}_{3}$ is significantly lower than the other results. These differences in the theoretical studies may originate from the different density-functional -besed electronic structure methods. Unfortunately, there are no theoretical and experimental results for comparing with the present work for $\mathrm{Sb}_{2} \mathrm{Te}_{3}$. The elastic constants $C_{11}$ and $C_{33}$ measure the a- and c- direction resistance to linear compression, respectively. The calculated $C_{33}$ for $\mathrm{Bi}_{2} \mathrm{Te}_{3}$ is lower than the $C_{11}$, whereas the calculated $C_{11}$ for $\mathrm{Sb}_{2} \mathrm{Te}_{3}$ is lower than the $C_{33}$. Thus, the $\mathrm{c}$ (a) axis for $\mathrm{Bi}_{2} \mathrm{Te}_{3}(\mathrm{Sb} 2 \mathrm{Te} 3)$ are more compressible than the a (c) axis.

A problem arises when single crystal samples are not available, since it is then not possible to measure the individual elastic constants. Instead, the polycrystalline bulk modulus $(B)$ and shear modulus $(G)$ may be determined. There are two approximation methods to calculate the polycrystalline modulus, namely, the Voigt method and the Reuss method [28-30]. For specific cases of rhombohedral lattices, the Reuss shear modulus $\left(G_{R}\right)$ and the Voigt shear modulus $\left(G_{V}\right)$ are

$$
\begin{aligned}
G_{V} & =\frac{1}{30}\left[M+12 C_{44}++12 C_{66}\right], \\
G_{R} & =\frac{5}{2}\left(C^{2} C_{44} C_{66}\right) /\left[3 B_{V} C_{44} C_{66}+C^{2}\left(C_{44}+C_{66}\right)\right]
\end{aligned}
$$

and the Reuss bulk modulus $\left(B_{R}\right)$ and Voight bulk modulus $\left(B_{V}\right)$ are defined as

$$
\begin{aligned}
& B_{R}=C^{2} / M \\
& \mathrm{~B}_{V}=\frac{1}{9}\left[2\left(C_{11}+C_{12}\right)+4 C_{13}+C_{33}\right]
\end{aligned}
$$

where, the abbreviations are $C^{2}=C_{33}\left(C_{11}+C_{22}\right)-2 C_{13}^{2}$, $M=C_{11}+C_{12}+2 C_{33}-4 C_{13}$. Using energy considerations Hill [31] proved that the Voigt and Reuss equations represent upper and lower limits of the true polycrystalline constants, and recommended that a practical estimate of the bulk and shear moduli were the arithmetic means of the extremes. Hence, the elastic moduli of the polycrystalline material can be approximated by Hill's average and for shear moduli and bulk moduli it is

$$
G=\frac{1}{2}\left(G_{R}+G_{V}\right) \text { and } B=\frac{1}{2}\left(B_{R}+B_{V}\right)
$$

The Young's modulus, $E$, and Poisson's ratio, $v$, for an isotropic material are given by

$$
E=\frac{9 B G}{3 B+G} \text { and } v=\frac{3 B-2 G}{2(3 B+G)}
$$

respectively [32,33]. Using the relations given above the calculated bulk modulus, shear modulus, Young's modulus, and Poisson's ratio for $\mathrm{Sb}_{2} \mathrm{Te}_{3}$ and $\mathrm{Bi}_{2} \mathrm{Te}_{3}$ are give Table 3 .

It is known that isotropic shear modulus and bulk modulus are a measure of the hardness of a solid. The bulk modulus is a measure of resistance to volume change by an applied pressure, whereas the shear modulus is a measure of resistance to reversible deformations upon shear stress [34]. Therefore, isotropic shear modulus is better predictor of hardness than the bulk modulus. The isotropic shear modulus, a measurement of resistance to shape change, is more pertinent to hardness and the larger shear modulus is mainly due to its larger $C_{44}$. The calculated isotropic shear modulus and bulk modulus are 53.2, 32.5 $\mathrm{GPa}$ and 39.7, 24.8 $\mathrm{GPa}$ for $\mathrm{Sb}_{2} \mathrm{Te}_{3}$ and $\mathrm{Bi}_{2} \mathrm{Te}_{3}$, respectively. The calculated bulk modulus for $\mathrm{Bi}_{2} \mathrm{Te}_{3}$ is a good agreement with experimental (0 K) [30] value. However, the bulk modulus is higher (about $7 \%$ and $11 \%$ ) than the theoretical results. The calculated shear modulus for $\mathrm{Sb}_{2} \mathrm{Te}_{3}$ is higher than $\mathrm{Bi}_{2} \mathrm{Te}_{3}$ compound.

According to the criterion in refs. [34,35], a material is brittle (ductility) if the $B / G$ ratio is less (high) than 1.75 . The value of the $B / G$ is less than 1.75 for $\mathrm{Sb}_{2} \mathrm{Te}_{3}$ and $\mathrm{Bi}_{2} \mathrm{Te}_{3}$. Hence, these materials behave in a brittle manner.

TABLE 3. The calculated isotropic bulk modulus (B, in GPa), shear modulus (G, in GPa), Young's modulus (E, in GPa) and Poisson's ratio.

\begin{tabular}{llcclc}
\hline Material & Reference & $\boldsymbol{B}_{\boldsymbol{H}}$ & $\boldsymbol{G}_{\boldsymbol{H}}$ & v & $\boldsymbol{E}$ \\
\hline $\mathrm{Sb}_{2} \mathrm{Te}_{3}$ & Present & 53.2 & 32.5 & 0.246 & 80.9 \\
& & & & & \\
$\mathrm{Bi}_{2} \mathrm{Te}_{3}$ & Present & 39.7 & 24.8 & 0.241 & 61.6 \\
& Exp. ${ }^{\mathrm{a}}(280 \mathrm{~K})$ & 37.4 & & & 54.2 \\
& Exp. $^{\mathrm{a}}(0 \mathrm{~K})$ & 39.5 & & & - \\
& Theory $^{\mathrm{b}}(\mathrm{K})$ & 34.4 & & & 52.5 \\
& Theory $^{\mathrm{b}}(300 \mathrm{~K})$ & 31.6 & & & 51.4 \\
\hline${ }^{\mathrm{a}}{ }^{\mathrm{C} e f e r e n c e}[30]$ & & & & &
\end{tabular}

Young's modulus is defined as the ratio of stress and strain, and used to provide a measure of the stiffness of the solid. The material is stiffer if the value of Young's modulus is high. In this context, due to the higher value of Young's 
modulus (80.9 GPa) $\mathrm{Sb}_{2} \mathrm{Te}_{3}$ compound is relatively stiffer than $\mathrm{Bi}_{2} \mathrm{Te}_{3}(61.6 \mathrm{GPa})$.

The value of the Poisson's ratio is indicative of the degree of directionality of the covalent bonds. The value of the Poisson's ratio is small $(v=0.1)$ for covalent materials, whereas for ionic materials a typical value of $v$ is 0.25 [36]. The calculated Poisson's ratios are about 0.246, 0.241 for $\mathrm{Sb}_{2} \mathrm{Te}_{3}$ and $\mathrm{Bi}_{2} \mathrm{Te}_{3}$, respectively. Therefore, the ionic contribution to inter atomic bonding for these compounds is dominant. The $v=0.25$ and 0.5 are the lower and upper limits, respectively, for central force solids [37]. Our $v$ values are close to the value of 0.25 indicating inter atomic forces are weightlessly central forces in $\mathrm{Sb}_{2} \mathrm{Te}_{3}$ and $\mathrm{Bi}_{2} \mathrm{Te}_{3}$.

TABLE 4. The calculated shear anisotropic factors $\mathrm{A}_{1}, \mathrm{~A}_{2}, \mathrm{~A}_{3}$, and $\mathrm{A}_{\mathrm{B}}, \mathrm{A}_{\mathrm{G}}$

\begin{tabular}{llcccc}
\hline Material & Reference & $\boldsymbol{A}_{1}$ & $\boldsymbol{A}_{2}$ & $\mathbf{A}_{\mathbf{B}} \mathbf{( \% )}$ & $\mathbf{A}_{\mathbf{G}}(\mathbf{\%})$ \\
\hline $\mathrm{Sb}_{2} \mathrm{Te}_{3}$ & Present & 1.97 & 1.00 & 3.01 & 5.39 \\
$\mathrm{Bi}_{2} \mathrm{Te}_{3}$ & Present & 1.81 & 1.00 & 0.10 & 5.71 \\
\hline
\end{tabular}

The calculation of the elastic anisotropy is well established in the crystal physics. The elastic anisotropy arises from both shear anisotropy and the anisotropy of linear bulk modulus. For trigonal materials, the shear anisotropic factors for $\{100\}$ shear plane in $\langle 010\rangle$ and $<011\rangle$ directions are $A_{1}=4 C_{44} /\left(C_{11}+C_{33}-2 C_{13}\right)$ and for $\{001\}$ shear plane in $<010>$ and $<011>$ directions are $A_{2}=2 C_{66} /\left(C_{11}-C_{12}\right)$ [38].

The calculated $A_{1}$ and $A_{2}$ for $\mathrm{Sb}_{2} \mathrm{Te}_{3}$ and $\mathrm{Bi}_{2} \mathrm{Te}_{3}$ are given in Table 4. A value of unity means that the crystal exhibits isotropic properties while values other than unity represent varying degrees of anisotropy. From Table 4, it can be seen that $\mathrm{Sb}_{2} \mathrm{Te}_{3}$ and $\mathrm{Bi}_{2} \mathrm{Te}_{3}$ exhibit low anisotropy. Another way of measuring the elastic anisotropy is given by the percentage of anisotropy in the compression $\left(\mathrm{A}_{\mathrm{B}}\right)$ and shear $\left(\mathrm{A}_{\mathrm{G}}\right)[32,33$, 39].

$$
A_{B}=\frac{B_{V}-B_{R}}{B_{V}+B_{R}} \times 100 \text { and } A_{G}=\frac{G_{V}-G_{R}}{G_{V}+G_{R}} \times 100
$$

The percentage anisotropy values have been computed for $\mathrm{Sb}_{2} \mathrm{Te}_{3}$ and $\mathrm{Bi}_{2} \mathrm{Te}_{3}$, and are shown in Table 4. For these compounds, it can be seen that the anisotropy in compression is small and the anisotropy in shear is high. $\mathrm{Sb}_{2} \mathrm{Te}_{3}$ compound exhibits relatively high bulk anisotropy between these compounds.

TABLE 5. The density, longitudinal, transverse, and average elastic wave velocities together with the Debye temperature.

\begin{tabular}{cccccc}
\hline Material & Reference & $\boldsymbol{v}_{\mid}(\boldsymbol{m} / \boldsymbol{s})$ & $\boldsymbol{v}_{\boldsymbol{t}}(\boldsymbol{m} / \boldsymbol{s})$ & $\boldsymbol{v}_{\boldsymbol{m}}(\boldsymbol{m} / \boldsymbol{s})$ & $\theta_{\boldsymbol{D}}(\boldsymbol{K})$ \\
\hline $\mathrm{Sb}_{2} \mathrm{Te}_{3}$ & Present & 3840 & 2227 & 2472 & 232.3 \\
$\mathrm{Bi}_{2} \mathrm{Te}_{3}$ & Present & 3040 & 1776 & 1969 & 181.3 \\
\hline
\end{tabular}

The Debye temperature is known as an important fundamental parameter closely related to many physical properties such as specific heat and melting temperature. At low temperatures the vibrational excitations arise solely from acoustic vibrations. Hence, at low temperatures the Debye temperature calculated from elastic constants is the same as that determined from specific heat measurements. We have calculated the sound velocities and the Debye temperature by using the common relation given in Ref. [40-42] for $\mathrm{Sb}_{2} \mathrm{Te}_{3}$ and $\mathrm{Bi}_{2} \mathrm{Te}_{3}$.

\section{Electronic Properties}

The energy band structures calculated using LDA for $\mathrm{Sb}_{2} \mathrm{Te}_{3}$ and $\mathrm{Bi}_{2} \mathrm{Te}_{3}$ are shown in Fig. 1. As can be seen in Fig. 1, the $\mathrm{Sb}_{2} \mathrm{Te}_{3}$ and $\mathrm{Bi}_{2} \mathrm{Te}_{3}$ compounds have an direct band gap semiconductor with the values $0.093 \mathrm{eV}$ and $0.099 \mathrm{eV}$, respectively. The top of the valance band and the bottom of the conduction band for both compounds positioned at the $\Gamma$ point of BZ. In conclusion, our band gap values obtained are good agreement with theoretical values and the band gaps have same character with given in Ref. [6, 7] . Band structures of $\mathrm{Sb}_{2} \mathrm{Te}_{3}$ and $\mathrm{Bi}_{2} \mathrm{Te}_{3}$ single crystals are compared, band structures of these crystals are highly resemble one another. Thus, on formation of the band structures of $\mathrm{Sb}_{2} \mathrm{Te}_{3}$ and $\mathrm{Bi}_{2} \mathrm{Te}_{3}$ the $5 \mathrm{~s} 5 \mathrm{p}$ orbitals of Te atoms are more dominant than $5 \mathrm{~s} 5 \mathrm{p}$ and $6 \mathrm{~s} 6 \mathrm{p}$ orbitals of $\mathrm{Sb}$ and $\mathrm{Bi}$ atoms.
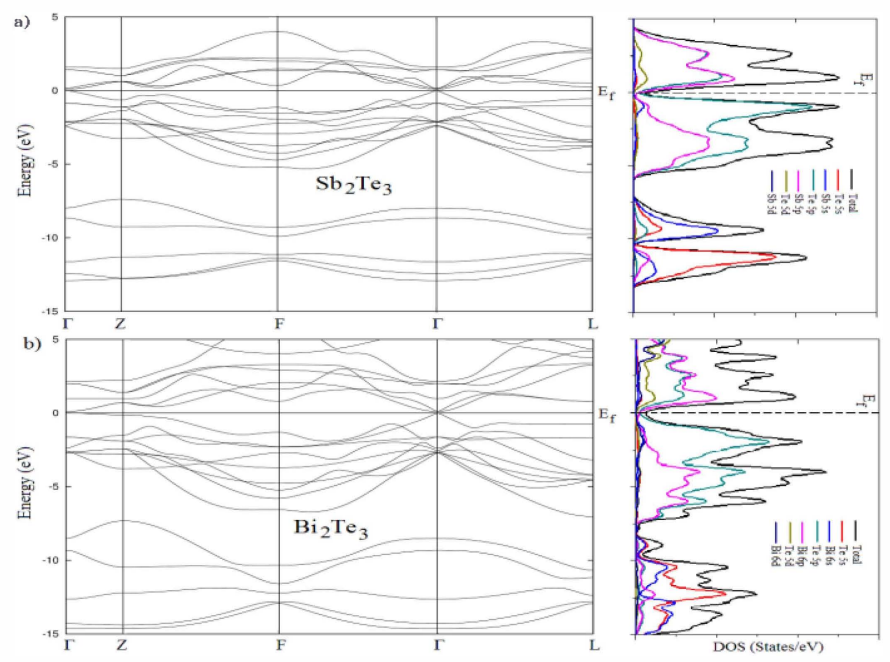

Fig.1. Energy band structure, the total (DOS) and projected density of states for a) $\mathrm{Sb}_{2} \mathrm{Te}_{3}$ and b) $\mathrm{Bi}_{2} \mathrm{Te}_{3}$.

The total and partial densities of states of $\mathrm{Sb}_{2} \mathrm{Te}_{3}$ and $\mathrm{Bi}_{2} \mathrm{Te}_{3}$ are illustrated in Fig. 1. As you can see, from this figure, the lowest valence bands occur between about -14 and $-12 \mathrm{eV}$ are dominated by $\mathrm{Sb} 5 \mathrm{~s}$ and $\mathrm{Bi}$ 6s states while valence bands occur between about -12 and $-10 \mathrm{eV}$ are dominated by Te $5 \mathrm{~s}$ states. The highest occupied valance bands are essentially dominated by Te $5 p$ states. The $5 p(6 p)$ states of $\mathrm{Sb}$ (Bi) atoms are also contributing to the valance bands, but the values of densities of these states are so small compared to Te $5 p$ states. The lowest unoccupied conduction bands just above Fermi energy level are dominated by $\mathrm{Sb} 5 \mathrm{p}$ and $\mathrm{Bi} 6 \mathrm{p}$ states.

\section{CONCLUSION}

In present work, we have made a detailed investigation of the structural, electronic, and mechanical of the $\mathrm{Sb}_{2} \mathrm{Te}_{3}$ and $\mathrm{Bi}_{2} \mathrm{Te}_{3}$ compounds using the density functional methods. The 
results of the structural optimization implemented using the LDA are in good agreement with the experimental and theoretical results. The elastic constants obtained using the stress-strain method show that these compounds are mechanically stable. The related mechanical properties like shear modulus, Young's modulus, Poisson's ratio, Debye temperature, and shear anisotropic factors, sound velocities, and Debye temperature are calculated and discussed. The band gap calculated by using LDA for the $\mathrm{Sb}_{2} \mathrm{Te}_{3}$ and $\mathrm{Bi}_{2} \mathrm{Te}_{3}$ are direct band gap $0.093 \mathrm{eV}$ and $0.099 \mathrm{eV}$, respectively.

\section{REFERENCES}

[1] C. L. Kane and E.J. Mele, " $\mathrm{Z}_{2}$ topological order and the quantum spin hall effect" Phys. Rev. Lett., vol. 95, pp. 146802.1-4, 2005.

[2] B. A. Berneving and S. C. Zhang, "Quantum spin hall effect" Phys. Rev. Lett., vol. 96, pp. 106802.1-4, 2006.

[3] J. E. Moore and L. Balents, "Topological invariants of time-reversalinvariant band structures.” Phys. Rev. B, vol. 75, pp. 121306.1-4, 2007.

[4] L. Fu, C. L. Kane, and E. J. Mele, "Topological insulators in three dimensions.” Phys. Rev. Lett., vol. 98, pp. 106803.1-4, 2007

[5] L. Fu and C. L. Kane, "Topological insulators with inversion symmetry." Phys. Rev. B., vol. 76, pp. 045302.1-17, 2007.

[6] W. Zhang, R. Yu, H. J. Zhang, X. Dia, and Z. Fang, "First-principles studies of the three-dimensional strong topological insulator $\mathrm{Bi}_{2} \mathrm{Te}_{3}$, $\mathrm{Bi}_{2} \mathrm{Se}_{3}$ and $\mathrm{Sb}_{2} \mathrm{Te}_{3}$." New J Phys., vol. 12, pp. 065013.1-14, 2010.

[7] W. Zhang, C. H. Liu, X. L. Qi, X. Dia, Z. Fang, and S. C.Zhang, "Topological insulators in $\mathrm{Bi}_{2} \mathrm{Te}_{3}, \mathrm{Bi}_{2} \mathrm{Se}_{3}$ and $\mathrm{Sb}_{2} \mathrm{Te}_{3}$ with a single Dirac cone on the surface." Nature Physics. Vol. 5, pp. 438-442, 2009.

[8] L. G. Khvostantsev, A. I. Orlov, N. K. Abrikosov, T. E. Svechnikova, and S. N. Chizhevskaya, "Thermoelectric properties and phase transitions in $\mathrm{Bi}_{2} \mathrm{Te}_{3}$ under hydrostatic pressure up to $9 \mathrm{GPa}$ and temperature up to 300 C.” Phys. Stat. Sol (a)., vol. 71, pp. 49-53, 1982.

[9] J. I. Zhang, S. J. Zhang, H. M. Weng, W. Zhang, L. X. Yang, Q. Q. Liu, S. M. Feng, X. C. Wang, R. C. Yu, L. Z. Cao, L. Wang, W. G. Yang, H. Z. Liu, W. Y. Zhao, S. C. Zhang, X. Dai, Z. Fang, and C. Q. Jin; "Pressure-induced superconductivity in topological parent compound $\mathrm{Bi}_{2} \mathrm{Te}_{3}$." Proc. Nat. Acad. Sci., vol. 108, pp. 24-28, 2011.

[10] D. D. Frari, S. Diliberto, N. Stein, and J. M. Lecuire; "Comparative study of the electrochemical preparation of $\mathrm{Bi}_{2} \mathrm{Te}_{2} \mathrm{Sb}_{2} \mathrm{Te}_{3}$ and $\left(\mathrm{Bi}_{x} \mathrm{Sb}_{1}\right.$. х) $)_{2} \mathrm{Te}_{3}$." Thin Solid Films, vol. 483, pp. 44-49, 2005.

[11] B. C. Sales; "Thermoelectric materials." Science, vol. 295, pp. 12481249, 2002.

[12] M. J. Huang, R. H. Yen, and A. B. Wang; "The influence of the Thomson effect on the performance of a thermoelectric cooler." Int. J. Heat Mass Transfer, vol. 48, pp. 413-418, 2005.

[13] P.P Dradyumnan and P.P Swathikrishnan; "Thermoelectric properties of $\mathrm{Bi}_{2} \mathrm{Te}_{3}$ and $\mathrm{Sb}_{2} \mathrm{Te}_{3}$ and its bilayer thin films." Indian J. Pure and Appl. Phys., vol. 48, pp. 115-120, 2010.

[14] G. Wang and T. Cagin; "Electronic structure of the thermoelectric materials $\mathrm{Bi}_{2} \mathrm{Te}_{3}$ and $\mathrm{Sb}_{2} \mathrm{Te}_{3}$ from first-principles calculations." Phys. Rev. B, vol. 76, pp. 075201.1-8, 2007.

[15] B. L. Huang, and M. Kaviany; "Ab initio and molacular dynamics predictions for electron and phonon transport in bismuth telluride." Phys. Rev. B, vol. 77, pp. 125209.1-19, 2008.

[16] J. W. Kohn, and L. J. Sham; "Self-consistent equations including exchange and correlation effects." Phys. Rev., vol. 140, pp. A1133A1138, 1965.

[17] D. M. Ceperley and M. J. Adler; "Ground state of the electron gas by a stochastic method." Phys. Rev. Lett., vol. 45, pp. 566-569, 1980.

[18] P. Perdew and A. Zunger; "Self-interaction correction to densityfunctional approximations for many-electron systems." Phys. Rev. B, vol. 23, pp. 5048-5079, 1981.

[19] P. Ordejón, E. Artacho, and J. M. Sole; "Self-consistent order-N density-functional calculations for very large systems." Phys. Rev. B, vol. 53, pp. R10441-R10444, 1996;53.
[20] J. M. Soler, E. Artacho, J. D. Gale, A. García, J. Junquera, P. Ordejón, and D. Sánchez-Portal; "The SIESTA method for ab initio order-N materials simulation.“ J. Phys. Condens. Matt., vol. 14, pp. 2745-2779, 2002.

[21] O. F. Sankey and D. J. Niklewski; "Ab initio multicenter tight-binding model for molecular-dynamics simulations and other applications in covalent systems." Phys. Rev. B, vol. 40, pp. 3979-3995, 1989.

[22] N.Troullier and J. L. Martins; "Efficient pseudopotantials foe planewave calculations." Phys. Rev. B, vol. 43, pp. 1993-2006, 1991.

[23] F. D. Murnaghan; "The compressibility of media under extreme pressures." Proc. Natl. Acad. Sci. U.S.A., vol. 50, pp. 244-247, 1944.

[24] R. W. G. Wyckoff; “Crystal Structures.” New York: Wiley; 1964;2:30.

[25] S. Q. Wu, Z. F. Hou, and Z. Z. Zhu; "Ab initio study on the structural and elastic properties of MAISI $(\mathrm{M}=\mathrm{Ca}, \mathrm{Sr}$, and $\mathrm{Ba}$ )“ Solid State Comm., vol. 143, pp. 425-428, 2007.

[26] J. O.Jonkins, J. A. Rayne, and R. W. Ure, Phys Rev B, vol. , pp. 3171, 1922.

[27] W. Kullmann, G. Eichorm, H. Rauh, R. Geick, G. Eckold, and U. Steigenberger; "Lattice dynamics and phonon dispersion in the narrow gap semiconductor $\mathrm{Bi}_{2} \mathrm{Te}_{3}$ with sandwich structure" Phys. Status Solidi B, vol. 162, pp. 125-140, 1990.

[28] W. Voight, Lehrbook der kristallphysik, Teubner, Leipzig, 1928.

[29] A. Z. Reuss; Angew. Math. Mech., vol. 49, pp. 9, 1929.

[30] S. Aydın and M. Şimşek; "The mechanical properties of $\mathrm{C}_{\mathrm{a}} \mathrm{X}_{6}(\mathrm{X}=\mathrm{B}$ and C)." Nonlinear and Complex Dynamics: App. In Phy., pp. 127-133, 2011 .

[31] R. Hill, "The elastic behaviour of a crystalline aggregate" Proc. Phys. Soc. A, vol. 65, pp. 349-354, 1952.

[32] K. B. Panda and K. S. R. Chandran; “ First principles determination of elastic constants and chemical bonding of titanium boride (TiB) on the basis of density functional theory" Acta Mater., vol. 54, pp. 1641-1657, 2006.

[33] P. Ravindran, L. Fast, P. A. Korzhavyi, B. Johansson, J. Wills, and O. Eriksson; "Density functional theory for calculation of elastic properties of orthorhombic crystals: Application to TiSi2" J. Appl. Phys., vol. 84, pp. 4891-4904, 1998.

[34] I. R. Shein and A. L. Ivanovskii ; "Elastic properties of mono- and polycrystalline hexagonal $\mathrm{AlB}_{2}$-like diborides of $\mathrm{s}, \mathrm{p}$ and $\mathrm{d}$ metals from first-principles calculations" J. Phys: Condens. Matter., vol. 20, pp. 415218-9, 2008.

[35] S. F. Pogh; "Relations between the elastic moduli and the plastic properties of polycrystalline pure metals" Phil. Mag.vol. 45, pp. 823843, 1954.

[36] V. V. Bannikov, I. R. Shein, and A. L. Ivanovskii ; "Electronic structure, chemical bonding and elastic properties of the first thorium-containing nitride perovskite $\mathrm{TaThN}_{3}$ " Phys. Status Solidi Rapid Res. Lett., vol. 1, pp. 89-91, 2007.

[37] H. Fu, D. Li, F. Peng, T. Gao, and X. Cheng, "Ab initio calculations of elastic constants and thermodynamic properties of $\mathrm{NiAl}$ under high pressures“ Comput. Mater. Sci. Vol.44, pp. 774-778, 2008.

[38] P. Ravindran, L. Fast, P. A. Korzhavyi, B. Johanson, J. Wills, and O. Eriksson; "Density functional theory for calculation of elastic properties orthorhombic crystals: Application to $\mathrm{TiSi}_{2} \mathrm{~J}$. Appl.Phys., vol. 84, pp. 4891-4905, 1998.

[39] D. H. Chung and W. R. Buessem, in Anisotropy in Single Crystal Refractory Compounds, F. W. Vahldiek and S. A. Mersol, eds., Plenum Press: New York, 1968.

[40] I. Johnston, G. Keeler, R. Rollins, S. Spicklemire, Solids State Physics Simulations: The Consortium for Upper-Level Physics Software, Wiley: New York, 1996

[41] O. L. Anderson; "A simplified method for calculating the Debye temperature from elastic constants" J. Phys. Chem. Solids, vol. 24, pp. 909-917, 1963.

[42] E. Schreiber, O. L. Anderson, and N. Soga, Elastic Constants and their Measurements, McGraw-Hill: New York, 1973. 